\title{
Deep Sea Investigations by Submarine Observation Chamber.
}

ON June 11,1930 , in lat. $32^{\circ} 16^{\prime} \mathrm{N}$., long. $64^{\circ} 39^{\prime} \mathrm{W}$. , in the Atlantic Ocean off Bermuda, Dr. William Beebe, accompanied by Mr. Otis Barton, descended to a depth of 1426 feet below the surface of the sea. ${ }^{1}$

This announcement marks a new era in the exploration of the sea. All previous diving records shrink into insignificance compared with this depth; it was with no wish for record-making achievements that the descent was undertaken, but a real explorer's desire to see the animals beneath the waters as they live and not at second-hand from the collections of deep sea nets.

The construction of the chamber was financed by Mr. Barton, and he and Dr. Beebe, working from the New York Zoological Society's Oceanographic Expedition's headquarters at Nonsuch Island, have now made several descents, of which three were to a depth of 800 feet and one to 1426 feet. The chamber is a steel sphere $57 \cdot 3$ in. in outside diameter and $1 \frac{1}{2}$ in. thick. Observations could be made through a 6 in. diameter port fitted with a quartz window. Outside the window was hung a bag of decayed fish and some baited hooks, and a strong electric searchlight could be used to illumine the surrounding water. Telephonic communication was maintained with the ship above and a supply of oxygen carried.

One of the most striking phenomena was the "blue brilliance of the watery light to the naked eye, long after every particle of colour had been drained from the spectrum". The visual degeneration of the spectrum was observed, in connexion with an intensity metre. In Dr. Beebe's own words: " The red had gone completely a few feet down . . . ; orange had been absorbed at sixty feet below the surface and yellow at less than 400 . At our depth (800 feet) lavender, too, was non-existent, together with the two opposite ends of the spectrum, infra-red and ultraviolet, while green still persisted, but greatly diluted. All that remained to our straining eyes were violet and blue, but blue such as no living man had ever seen."

It proved quite possible to observe pelagic animals drifting and swimming past the window, such as medusæ, shrimps, and fish, and about a dozen true bathypelagic fish were identified. A very interesting result of these observations was the presence of certain species of fish and invertebrates in water layers well above the depth at which their occurrence is first indicated by net catches in the daytime.

Four descents have also been made in water up to 350 feet in depth along the shelving bottom of the Bermudian insular shelf as the vessel drifted seawards. Such exploration revealed a new fish fauna at these offshore depths, the recognisable shore fish also being of great size.

The observations will be continued another year, and it is to be hoped that this new weapon of marine research has come to stay and that similar submarine observation chambers may be built in time for a study of the floor of shallower seas and the habits of food fishes. Already shallow water diving has proved its scientific value. We shall await Dr. Beebe's and Mr. Barton's full reports with great interest.

${ }^{1}$ Science, vol. 72 , No. 1854, July 11, 1930, pp. 27-28. “A New Method of Deep Sea Observation First-hand." "By Henry Fairfield Osborn.

${ }^{2}$ New York Times, June 27, 1930.

\section{The Leakey-Harper Drawing Machine.}

$I^{\mathrm{N}}$ many branches of science, and more especially in zoology, palæontology, anthropology, and anatomy, it is often necessary to make illustrations of irregular and intricate objects, which must be true to scale and accurate in detail. It has been found that photography does not fulfil the requirements, and the illustrations have in the past been made by accurate freehand drawings. Such drawings require a large number of measurements to be made, and if a high degree of accuracy is required the work entailed is very considerable. If the specimen being drawn is of a fragile nature, considerable risks are involved because of the amount of handling entailed.

The drawing machine illustrated in Fig. I has been especially designed by the Cambridge Instrument Co., Ltd., 45 Grosvenor Place, London, S.W.1, to enable true-to-size drawings to be made quickly and conveniently, with the minimum amount of handling. It further makes it possible for drawings to be made of any of the six different views which represent six projections on to the sides of a cube surrounding the object, without moving the specimen after it has been once put into position.

This fact is of special importance in that branch of work for which the instrument was originally suggested by L. S. Leakey, namely, making drawings of human skulls, where it is often necessary to make drawings of the profile, full face, base, etc., with the skull orientated on the Frankfurt plane. The instrument is very easy to use and combines both greater accuracy and greater speed in the drawing of any object. The outline drawing of a skull that is illustrated in Fig. 2, including the teeth, sutures, and orifices, took forty-five minutes. A similar drawing done by the ordinary measurement and freehand method would have taken approximately twelve hours, whilst the degree of accuracy obtained on a complete set of freehand drawings could not equal that obtained by the drawing machine.

The principle of operation of the Leakey-Harper machine (Fig. 1) is as follows: A telescope, A, fitted with crosslines and with a horizontal line of sight, is fixed rigidly to a carriage that is capable of horizontal and vertical movement in a plane normal to its axis but so that the line of sight remains accurately parallel to its original direction. The horizontal and vertical movements of the telescope are obtained by rotating two hand wheels, one on the left hand, $B$, effecting the horizontal adjustment and one on the right, $C$, the vertical adjustment. Rigidly attached to the hand wheels, and at right angles to one another, are two long screws, one on the left hand carrying the telescope carriage, so that any rotation of the wheel moves the telescope in a horizontal direction. Rotation of the wheel on the right moves the telescope vertically. Attached to the base of the telescope carriage is a pencil, $D$, that inscribes in one plane on a sheet of paper the horizontal and vertical movements of the telescope.

Attached to the pencil is a circular soft iron plate that is supported above a solenoid by a helical spring; the pencil itself is fed through the solenoid so that the point is supported immediately above the paper; when a current is passed through the solenoid the soft iron plate is magnetically attracted and the pencil pulled down until it is in contact with the paper. When the circuit is broken the pencil is automatically raised from the paper.

No. 3171, VoL. 126] 